\title{
Functionalized Carboxylate Deposition for Rapid Sensitization of Dye-Sensitized Solar Cells
}

\author{
Venkataiah Mallam ${ }^{1}$, Sanjib Baral'2, Santosh Gyawali², Robert P. Oda', Hytham Elbohy², \\ Jeevan Nepal'2, Qiquan Qiao², Mahdi Farrokh Baroughi², and Brian A. Logue ${ }^{1 *}$
}

${ }^{1}$ Department of Chemistry and Biochemistry, ${ }^{2}$ Department of Electrical Engineering and Computer Science, South
Dakota State University, Brookings, SD, 57007, USA. Correspondence to: *brian.logue@sdstate.edu
KEYWORDS. Monolayer, Gas-phase deposition, Hybrid materials, Solar cell fabrication

\begin{abstract}
The current state-of-the-art dye loading process for modern dye-sensitized solar cells (DSCs), essentially unchanged for the last 24 years, entails dip-coating nanoporous $\mathrm{TiO}_{2}$ photoelectrodes in a concentrated solution of dye for an average of 16 hours. This process constitutes up to $80 \%$ of the fabrication time, leads to significant dye waste, and necessitates the use of organic solvents. A promising gas-phase deposition technique, coined Functionalized Carboxylate Deposition (FCD), was used to rapidly deposit a self-assembled monolayer of targeted $\alpha$-carbon modified carboxylic acid containing dye molecules on $\mathrm{TiO}_{2}$ photoelectrodes. The FCD process successfully reduced the dye loading time by $98 \%$ (i.e., 15-20 min compared to an average of $16 \mathrm{hr}$ ). Moreover, the FCD-sensitized photoelectrodes produced DSCs with equivalent or higher efficiencies than dip-coating for the dyes used (both in this study and by other researchers). The performance of FCD dye sensitization in this study indicates its potential applicability as a foundational technology for rapid fabrication of efficient DSCs.
\end{abstract}

\section{Introduction}

Dye-sensitized solar cells (DSCs), photoelectrochemical devices which convert sunlight to electricity, have attracted copious attention due to the use of relatively easy and low energy fabrication techniques, low cost materials, and relatively good power conversion efficiency ${ }^{1-5}$. Modern DSC research was pioneered by O'Regan and Grätzel ${ }^{6}$ when they used a nanoporous oxide semiconductor, a dye sensitizer, a liquid electrolyte, and a counter electrode to produce a solar cell with $7.9 \%$ power conversion efficiency. While all of these components are crucial for energy conversion, the dye sensitizer is responsible for initial absorption of photons with associated initiation of electron flow through the cell. After the modern DSC design was originally introduced in 1991, novel dye discovery quickly produced significant increases in cell efficiency, with the Ru-based N3 dye producing 10\% power conversion efficiency in $1993^{7}$. Since the introduction of N3, efficiencies have remained relatively constant, even though extensive work has been pursued on all components of DSCs. Currently, with the improvements in DSC technology, including breakthroughs in alternative dyes ${ }^{8,9}$, photoelectrodes ${ }^{10-14}$, and electrolytes ${ }^{7,15-22}$, efficiencies of laboratory-based DSC modules have only slightly increased to $13 \%{ }^{5}$ over the past 22 years. Although future work may uncover technology to significantly increase the efficiency of DSCs, other means of reducing the power generation cost are critically necessary to increase the feasibility of DSCs as an alternative energy generation technology. 
The typical DSC fabrication process includes preparation of photoelectrodes, dipcoating the photoelectrode with a dye sensitizer, loading a liquid electrolyte, preparing a counter electrode, and packaging ${ }^{23-27}$. Despite simplicity and relatively low energy consumption, the time required to complete this process typically extends beyond 22 hours, leading to limited throughput and cost-effectiveness of the technology. The dye-loading process, which takes 624 hours ${ }^{28-35}$, constitutes the main limiting factor in the duration of DSC production, consuming approximately $70 \%$ of the total DSC fabrication time ${ }^{36,37}$. A significant reduction in the duration of dye sensitization would allow higher throughput fabrication, potentially leading to lower-cost DSC technology.

Presented for the first time here, Functionalized Carboxylate Deposition (FCD) is a promising gas-phase deposition technique utilizing targeted $\alpha$-carbon modified carboxylic acids to rapidly deposit activated organic molecules into a self-assembled monolayer on oxide materials. The objective of this study was to evaluate FCD's ability to sensitize $\mathrm{TiO}_{2}$ photoelectrodes without significantly reducing DSC efficiency. If successful, FCD for DSC sensitization would greatly reduce the duration of dye deposition compared to the state-of-the-art, and with its other advantages, it may become a foundational fabrication technology in rapid and ultra-low cost DSC production.

\section{Results and discussion}

\section{DSC Dyes}

For FCD compatibility, dye molecules must evaporate or sublimate prior to thermal degradation (i.e., they must have relatively low molecular weight and good thermal stability) and contain a highly electron withdrawing functionality on the $\alpha$-carbon to the carboxylic acid. Dye molecules based on amino phenyl acrylic acid structures that satisfy these two requirements have been previously used as dye sensitizers ${ }^{38-41}$. Two dyes from this class, referred to as Dyes 1 and 2 (Fig. 1), were chosen for this study because they were postulated to be highly amenable to FCD sensitization, even though other dyes in this class have been shown to produce much higher efficiencies (some over 7\% 41,42 ). Therefore, because the current study is the first application of FCD for DSC sensitization, the ability to produce higher efficiency DSCs was sacrificed in order to increase the probability of successful FCD sensitization. Previously, Dyes 1 and 2 have produced efficiencies of $2.2-2.4 \%{ }^{38}$ and 2.39-3.3\% ${ }^{38-41}$, respectively. (Note: Dye 1 was referred to as $\mathbf{1 a}$ by Kitamura et al. ${ }^{38}$, and Dye $\mathbf{2}$ was referred to as $\mathbf{1 b}$ by Kitamura et al. ${ }^{38}$, TC1 by Xu et al. ${ }^{40}, \mathbf{L O}$ by Marinado et al. ${ }^{39}$, and TC by Teng et al. ${ }^{41}$.)

Dyes 1 and $\mathbf{2}$ were synthesized based on Knoevenagel condensation (see Supplementary Material for synthesis details). The two dyes exhibited a major absorbance band in the 350-450 $\mathrm{nm}$ range (Fig. S1) and excellent thermal stability, with Dyes 1 and 2 decomposing at $228^{\circ} \mathrm{C}$ and $240^{\circ} \mathrm{C}$, respectively (Fig. S2).

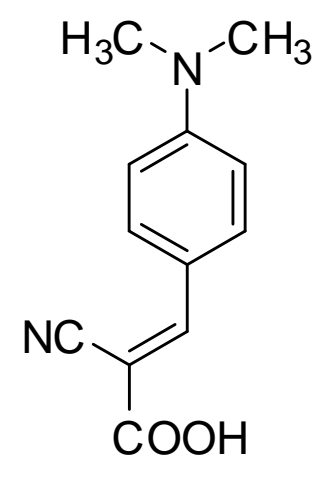

Dye 1

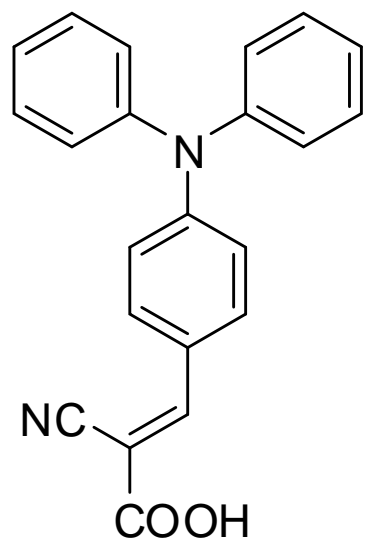

Dye 2
Fig. 1. Small molecular weight dyes for FCD sensitization of DSCs. (Z)-2-cyano-3-(4-(dimethylamino)phenyl)acrylic acid and (Z)-2-cyano-3-(4(diphenylamino)phenyl)-acrylic acid (referred to as Dyes $\mathbf{1}$ and 2, respectively) were synthesized generally according to the procedure of Kitamura et al. ${ }^{38}$ as outlined in Scheme S1. 


\section{Functionalized Carboxylate Deposition of Dye Sensitizers}

FCD is a gas-phase deposition technique which is used to rapidly deposit activated organic molecules on oxide materials, including very highly porous oxides (e.g., nanoporous $\mathrm{TiO}_{2}$ ). In the present study, FCD was accomplished in one of two ways: 1) a common grease-free two-piece glass sublimation apparatus (Figure 2A); and 2) a custom built FCD chamber (Figure 2B) with greater heater and vacuum control, more comprehensive monitoring of deposition conditions, and a greater vacuum range. For the sublimation glassware, solid dye was placed in the bottom piece of the apparatus and $\mathrm{TiO}_{2}$ photoelectrodes were affixed to the bottom of the condenser. The two pieces of the sublimation apparatus were secured together with a pinch clamp and a vacuum ( 181 Torr) was applied. The sublimation apparatus was subsequently immersed in a pre-heated oil bath $\left(30-40^{\circ} \mathrm{C}\right.$ below the decomposition temperature of the dye being deposited). The dyes were allowed to sublimate/evaporate and deposit on the $\mathrm{TiO}_{2}$ photoelectrodes for a prescribed duration, typically 20 minutes. The photoelectrodes were then washed and used to fabricate DSCs. In addition to the photoelectrode surface, dye condensed on the sides of the sublimation chamber and the condenser. This dye, along with weakly bound dye on the photoelectrode, was recovered by washing with acetone.

For the custom FCD chamber, a stationary cylindrical vacuum chamber was placed on top of a movable polished baseplate with a lab jack used for positioning. A feed through was affixed to the bottom of the baseplate and a heater (100 W) was fixed on top. A thermocouple was used to measure the temperature of the heater and a heater control circuit box was used to control the heater temperature. An aluminum crucible containing dye was placed on the heater and a glass container was used to cover the heater and crucible to limit contamination. To the sides of the glass container, photoelectrodes were affixed using double sided tape. The baseplate was lifted into position and a vacuum was initiated. A mass flow controller was used to control the vacuum at about 500 mTorr. The temperature was gradually increased to 180 and $210{ }^{\circ} \mathrm{C}$ for Dyes $\mathbf{1}$ and $\mathbf{2}$, respectively. After deposition was complete, the vacuum and heater were turned off, the photoelectrodes were removed, and the photoelectrodes were washed with acetonitrile and acetone. The glass container was also washed and dye was recovered for subsequent depositions.

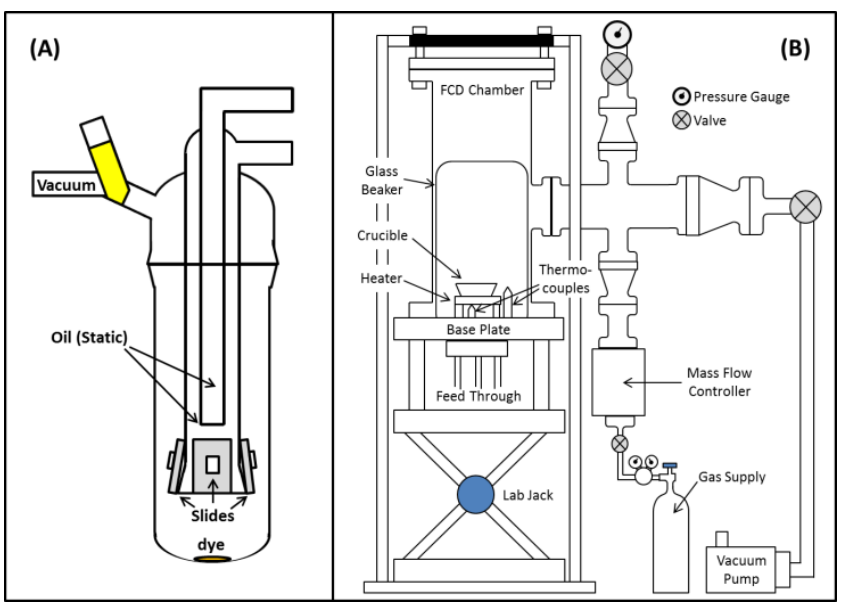

Fig. 2. Diagrams of the FCD chambers used in this study. A) Common sublimation glassware was used to initially evaluate FCD. B) A custombuilt FCD instrument was used for deposition of dyes for final DSC evaluation.

\section{FCD-sensitized DSCs}

\subsection{Deposition time}

FCD was initially tested using standard sublimation glassware (Fig. 2A) to deposit Dyes 1 and 2 onto $\mathrm{TiO}_{2}$ photoelectrodes for 5-60 minutes, and the efficiency of the resulting DSCs was evaluated. Fig. 3 shows the change in DSC efficiency as the FCD time was varied. After the efficiency was measured, the DSCs were deconstructed and the dye bound to the photoelectrode was desorbed by soaking in $0.1 \mathrm{M} \mathrm{KOH}$. The maximum absorbance of the desorbed dye is also plotted in Fig. 3. For comparison, DSCs were also fabricated by sensitization via dipcoating. The average efficiencies of the resulting 
DSCs and absorbance of the desorbed dyes are indicated in Fig. 3. Detailed performance and spectrophotometric data are provided in the Supplementary Material (specifically Table S1 and Fig. S5).

As seen in Fig. 3, the efficiency of the FCD-sensitized DSCs and the surface coverage increased up to 20 minutes. The efficiency then decreases while the surface coverage only slightly increases. The decrease in efficiency is more pronounced for Dye $\mathbf{2}$ than Dye $\mathbf{1}$. The increased efficiency over the first 20 minutes is predominately attributed to increased dye loading resulting in an increase in the $J_{s c}$ (Table S1) (Fig. 3). This conclusion is supported by the dye surface coverage (light blue squares) increasing at essentially the same rate as the efficiency (dark blue bars). Also, it is known that the surface coverage of dye molecules directly bonded to the $\mathrm{TiO}_{2}$ photoelectrode surface has a direct impact on the $\mathrm{J}_{\mathrm{sc}}$ of the resulting DSC ${ }^{43}$.

It was necessary to reevaluate the optimum deposition time to produce the maximum DSC performance when using the custom FCD apparatus. Deposition times of 5-20 minutes were evaluated. A similar trend was observed as with the sublimation glassware, but $15 \mathrm{~min}$ of dye deposition was found to produce the maximum DSC efficiency (Table S2). It is likely that the higher vacuum produced by the FCD apparatus allowed faster evaporation of the dyes and quicker mono-layer formation. The positioning of the photoelectrode slides may also have had an effect on the deposition rate, but the magnitude of this effect is currently unclear.

The rate of change of surface coverage with increasing FCD times shows a marked difference between the first 20 minutes and longer deposition times. This indicates that FCD sensitization of Dyes $\mathbf{1}$ and $\mathbf{2}$ is self-limiting, at least to some extent. Although the surface coverage is self-limiting, the DSC efficiency at FCD times greater than 20 minutes drops rapidly for Dye $\mathbf{2}$ and more slowly for Dye $\mathbf{1}$. The decrease in efficiency after $20 \mathrm{~min}$, with simultaneous slight in- creases in dye loading, is likely due to dye aggregation leading to inefficient electron transfer ${ }^{44}$. Aggregation leads to non-surface bound sensitizer molecules, resulting in photon capture without injection of the excited electron into the $\mathrm{TiO}_{2}$ semiconductor. This excited electron either
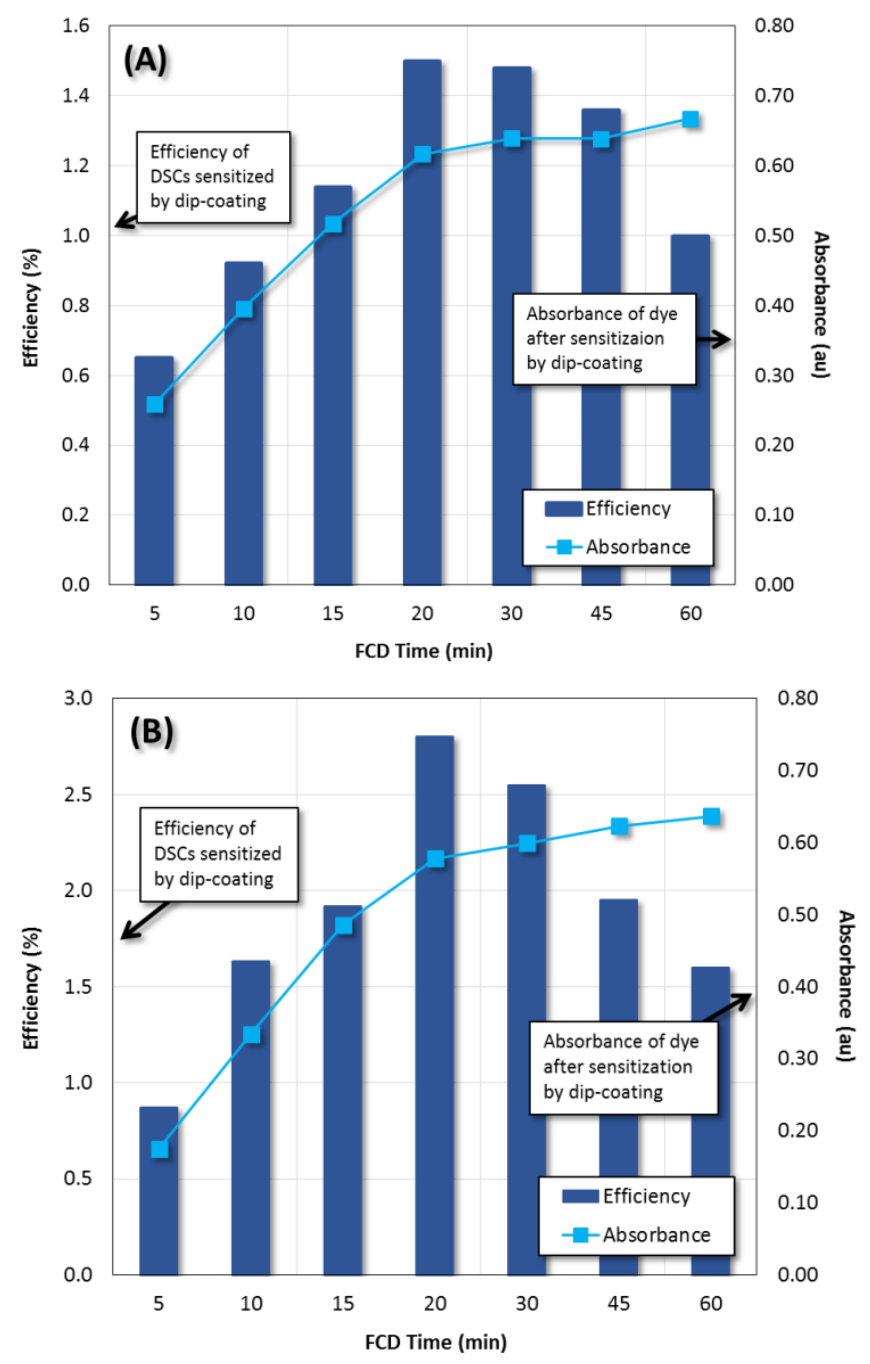

Fig. 3. Efficiencies of DSCs sensitized with Dyes 1 (A) and 2 (B) by dip-coating (24 hours) and FCD for various times. The absorbance of the dyes desorbed from the photoelectrode surface is also plotted. The optimum duration of FCD was 20 minutes with absorbance at longer deposition times slightly increasing, but efficiency decreasing (especially for Dye $\mathbf{2}$ ), likely both due to dye aggregation. The maximum efficiency and surface coverage of FCD-sensitized DSCs (at 20 $\min$ ) were $\geq 1.5$ times dip-coating. 
Table 1. Standard characterization metrics for DSCs produced using FCD (20 min) and dip-coating (24 h). FCD produced equivalent or better DSC performance as compared to dip-coating at a fraction of the time.

\begin{tabular}{cccccccc}
\hline Deposition mode & Dye & $\mathrm{J}_{\mathrm{sc}}\left(\mathrm{mA} / \mathrm{cm}^{2}\right)$ & $\mathrm{V}_{\mathrm{oc}}(\mathrm{mV})$ & Fill Factor & $\mathrm{R}_{\mathrm{s}}$ & $\mathrm{R}_{\text {sh }}$ & Efficiency (\%) \\
\hline FCD & 1 & 6.98 & 670 & 0.67 & 17.0 & 326 & 3.17 \\
FCD & 2 & 7.18 & 680 & 0.67 & 17.2 & 376 & 3.30 \\
Dip-coating & 1 & 5.31 & 740 & 0.66 & 29.8 & 277 & 2.62 \\
Dip-coating & 2 & 8.24 & 640 & 0.64 & 19.0 & 321 & 3.37 \\
\hline
\end{tabular}
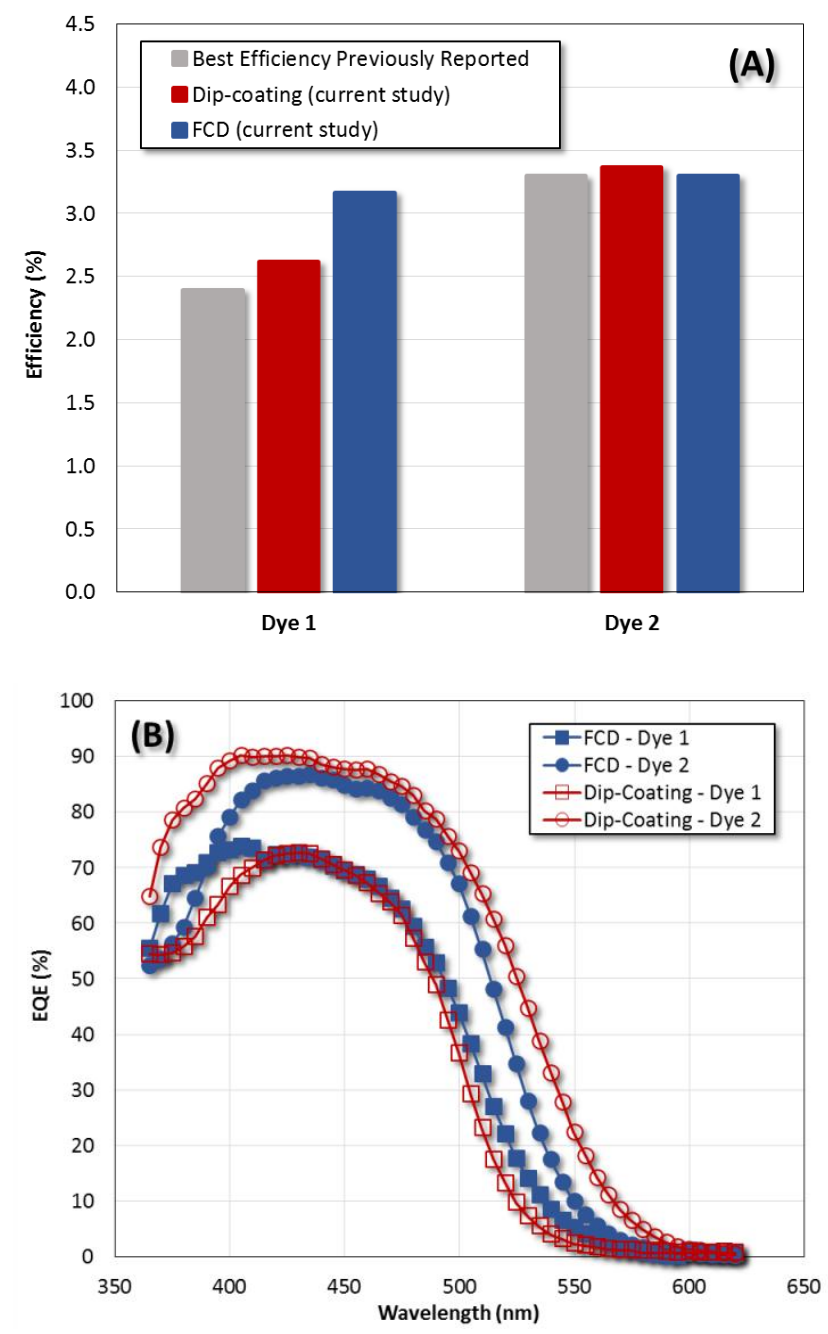

Fig. 4. Comparison of the efficiencies (A) and EQE (B) of DSCs sensitized with Dyes 1 (squares) and 2 (circles) by dip-coating ( $24 \mathrm{~h}$; open red symbols) and FCD (15 min; solid blue symbols). The efficiency of FCD-sensitized DSCs is $\geq 1.5$ times the efficiency of dip-coated DSCs. The efficiency increase is relatively consistent throughout the EQE. relaxes to the ground state or is transferred to the electrolyte where it acts to combine with vacant orbitals, decreasing productive electron flow and lowering the efficiency of the DSCs. A high energy electron from an excited dye molecule may also participate in the generation of reactive species that may degrade surfacebound dye molecules. Fig. 3 indicates that the sensitization of DSCs via may be delicate, with both "undersensitization" and "oversensitization" leading to a loss in efficiency.

\subsection{Dye sensitization by FCD and dip-coating}

DSCs were fabricated from $\mathrm{TiO}_{2}$ electrodes dyed with Dyes 1 and 2 by dip-coating (24 h) and FCD (15 min). The cell performance is shown in Fig. 4: (A) comparison of cell efficiencies, and (B) comparison of the external quantum efficiency (EQE) of the cells. Detailed performance data is also presented in Table 1 and Fig. S6.

DSCs fabricated using FCD (at the optimized deposition time) were 1.2 and 0.98 times, or $21 \%$ more and $2 \%$ less efficient for Dyes 1 and 2, respectively, when compared to dip-coating. Moreover, the efficiency of the Dye 2 FCDsensitized DSC was equivalent to the world record cell produced by dip-coating $\left(n=3.3 \%, \mathrm{~V}_{\text {oc }}=\right.$ $770 \mathrm{mV}$, fill factor $=0.67$ ), even though the $\mathrm{V}_{\text {oc }}$ was $90 \mathrm{mV}$ lower for FCD-sensitized cells ${ }^{38}$. As with the initial comparison of FCD to dip-coating (Fig. 3), the increased efficiency of FCD compared to dip-coating for Dye $\mathbf{1}$ was attributed mainly to increased dye loading, which was evident both visually and by the increase in $J_{s c}$ of 
approximately 1.3 times. The EQE curves for the dyes have similar shapes to their absorbance spectra, although they are red-shifted slightly, which is common for DSC dyes bound to $\mathrm{TiO}_{2}{ }^{45}$. The EQE behavior of the DSCs produced supports the $J_{s c}$ values found from the currentvoltage analysis of the DSCs (Table 1 ), with the EQE of Dye 1 being higher for FCD than dipcoating and the opposite for Dye 2.

The range of $\mathrm{V}_{\text {oc }} \mathrm{S}$ for the DSCs, $640-740$ $\mathrm{mV}$, was fairly narrow, and no trend was observed when comparing dip coating and FCD dye deposition. The fill factor for the DSCs was very consistent $0.64-0.67$, indicating the quality of the DSCs were similar for each dye and each sensitization method. To compare the cells made in this study to a standard dye molecule, DSCs were concurrently created under the same conditions with the Ru-based sensitizer, N719, by dip-coating. The overall efficiency of the N719based DSCs was $7.52 \%$. The fill factor (0.66) of the N719-based DSCs was essentially identical to the cells in Table 1, while the $\mathrm{V}_{\text {oc }}(750 \mathrm{mV})$ was higher than Dye 1 and 2-sensitized DSCs. As expected, the increased $\mathrm{J}_{\mathrm{sc}}$ for $\mathrm{N719}$ accounted for the majority of the efficiency difference between these cells and was attributed to the ability of N719 to absorb a wider range of the solar spectrum than the dyes used for this study.

\subsection{Dye utilization}

Currently, highly concentrated dye solutions (0.2-0.5 mM) are used for dip-coating 23, 2830, 33. Because the highest efficiency DSC dyes are costly 2, 46-48, recovery and/or limited use of these expensive dyes is essential for costeffective production of DSCs. In addition to rapid dye sensitization, FCD offers the potential to afford efficient dye use as a significant material cost advantage. Although the use of a common sublimation apparatus in this study demonstrates the ease and simplicity of FCD for sensitization and a significant portion of unused dye was recovered by washing the sublimation apparatus and photoelectrode with acetone, a more complex FCD apparatus would allow easier and higher dye recovery. Although not a feature of the custom FCD apparatus used in this study, better temperature control throughout the FCD apparatus (i.e., ensuring uniform heating of the vessel walls) would likely allow the dye to bond specifically to the photoelectrode. A cold trap would also allow direct condensation to a small area after deposition concludes. Considering these modifications to the FCD apparatus, DSC sensitization may ultimately require as low as microgram quantities of dye for laboratorybased cells. For example, using a standard DSC photoelectrode with a surface roughness of $100{ }^{10}$ and a grafting density of around one dye molecule per $2 \mathrm{~nm}$ of surface area, $18 \mu \mathrm{g} / \mathrm{cm}^{2}$ of Dye 1 would be necessary to cover the entire photoelectrode surface. For comparison, considering the relatively low molecular weight Dye $\mathbf{1}$, $0.8-2.2 \mathrm{mg}$ is necessary to produce a $20 \mathrm{~mL}$ solution for dip-coating. Assuming 100 slides can be dyed from the same solution, $147 \mu \mathrm{g} / \mathrm{cm}^{2}$ of dye is utilized, which is almost 10 times more than for FCD.

\section{Surface Characterization: Bonding and Film Growth}

\subsection{Growth of DSC sensitizer monolayer}

Kelvin Probe Force Microscopy (KPFM) was used to evaluate the surface coverage and growth mechanism of FCD using Dye 1 by mapping the surface potential of FCD-modified $\mathrm{TiO}_{2}$ ${ }^{49}$. Because KPFM requires a relatively smooth surface, a compact layer of $\mathrm{TiO}_{2}$ was used as the substrate instead of DSC photoelectrodes. Also, the amount of dye available for deposition was strictly controlled by creating a dilute solution of Dye 1 in methanol $(20 \mathrm{mg} / \mathrm{L})$, adding a specific volume of this solution to the sublimation apparatus $(0.3-30 \mathrm{~mL})$, and allowing the solvent to evaporate prior to FCD.

Fig. 5 shows the surface potential maps of the Dye 1 sensitized $\mathrm{TiO}_{2}$ compact layers (A-F) and the change in the average surface potential with increasing surface coverage of the dye (G; plotted as a change from non-sensitized compact layer $\mathrm{TiO}_{2}$ ). The surface potential maps show the gradual non-localized decrease in surface potential. This behavior suggests that there are a high number of nucleation sites on the $\mathrm{TiO}_{2}$ surface for the adsorption of the dye and that 
island formation (i.e., aggregation) is not the main growth mechanism for dye sensitization. The potential maps also show a very uniform

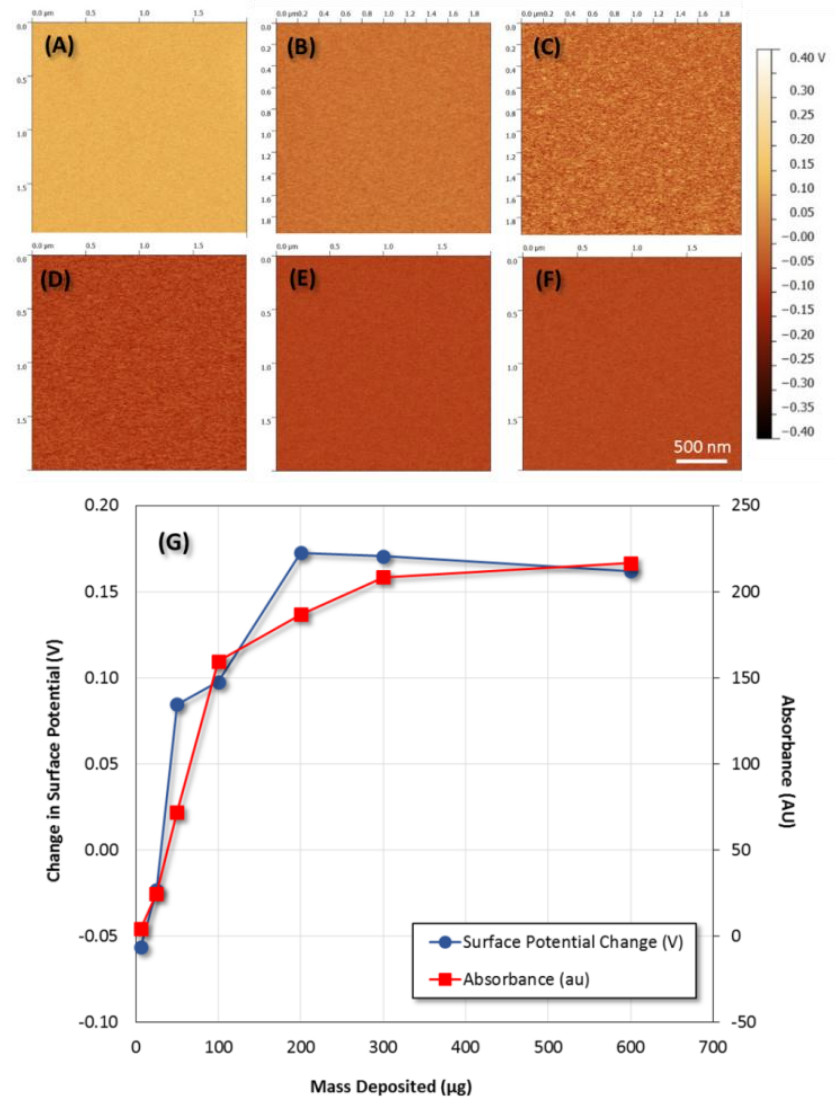

Fig. 5. Kelvin Probe Force Microscopy images of FCD-sensitized (Dye 1) $\mathrm{TiO}_{2}$ compact layers. The dye available for deposition was 25 (A) 50 (B) 100 (C) 200 (D) 300 (E) 600 (F) mg. The surface potential change (plotted as the absolute change from the surface potential of nonsensitized compact $\mathrm{TiO}_{2}$ ) and absorbance behavior of the dye are essentially identical and both indicate self-limiting behavior.

appearance when depositing greater than 200 $\mu \mathrm{g}$ of Dye 1 (Fig. 5E and F). This indicates a selflimiting process and uniform surface coverage under these conditions. The self-limiting nature of FCD deposition of Dye $\mathbf{1}$ is also confirmed by the behavior of surface coverage (as measured by absorbance of the dye desorbed from the compact layers) and average surface potential as a function of the amount of dye deposited (Fig. $5 \mathrm{G})$. Both surface coverage and change in surface potential approach a maximum, with very similar relative behavior. The large change in surface potential over the course of the experiment (approximately $220 \mathrm{mV}$ ), along with the uniform appearance of the surface coverage maps at large surface coverage, indicates that excellent surface coverage is achieved by FCD.

\subsection{Surface Bonding Mode}

FTIR analysis can be used to elucidate the binding mode of carboxylates on oxide surfaces using the Deacon-Philips rule ${ }^{50}$, which states: if the frequency separation of the asymmetric ( $v_{\text {as }}$ $\approx 1600$ to $1670 \mathrm{~cm}^{-1}$ ) and symmetric $\left(v_{\mathrm{s}} \approx 1350\right.$ to $\left.1390 \mathrm{~cm}^{-1}\right)$ stretch of the sodium carboxylate $(\Delta v$ $\left.=v_{\text {as }}\left(\mathrm{COO}^{-}\right)-v_{s}\left(\mathrm{COO}^{-}\right)\right)$is less than the $\Delta v$ of the $\mathrm{TiO}_{2}$-bound dye, the surface bonding mode is unidentate, otherwise it is bidentate (i.e., bidentate bridging or bidentate chelating). Inspection of the FTIR data (Supplemental Information; Figure S7 and Table S3) indicates that the binding mode of Dye 1 on $\mathrm{TiO}_{2}$ using FCD and dip-coating for sensitization is unidentate, whereas the binding mode for Dye $\mathbf{2}$ is bidentate (dip-coating or FCD). For each individual dye, the FTIR spectra for FCD and dip-coating are virtually indistinguishable, indicating that the bonding of the dyes is essentially the same, regardless of the deposition technique. This result further corroborates that dye loading is likely responsible for the increased efficiency and not differences in bonding produced by differences in the two sensitization techniques.

\section{Conclusions}

In this study, we introduced a novel gasphase self-assembled monolayer deposition technique, called Functionalized Carboxylate Deposition, for the sensitization of nanoporous $\mathrm{TiO}_{2}$ photoelectrodes for DSCs. Fig. 6 shows a visual depiction of the average time necessary for fabrication of DSCs with a breakdown of each individual process. FCD reduced the dye loading time by up to $98 \%$ compared to the current state-of-the-art dip-coating process, which produced a $67 \%$ reduction in the overall fabrication time. Moreover, FCD reduces dye sensitization from being the major contributor to fabrication time $(70 \%)$, to being the second fastest process in DSC fabrication (only 7\%). 
Not only was the dying time tremendously reduced, DSCs fabricated using FCD produced equivalent or increased efficiencies compared to dip-coating for the dyes tested with no change in dye-surface bonding. In fact, a world record efficiency was produced for Dye 1-based solar cells using FCD. Moreover, FCD has the ability to tremendously reduce the time, waste, and organic solvent use associated with DSC dye sensitization. The advantages of FCD, along with other recent developments in DSC research, including high efficiency all solid-state DSCs ${ }^{4}$ and increased efficiency dyes ${ }^{9}$, may lead to DSC technology contributing significantly to the world's alternative energy portfolio.

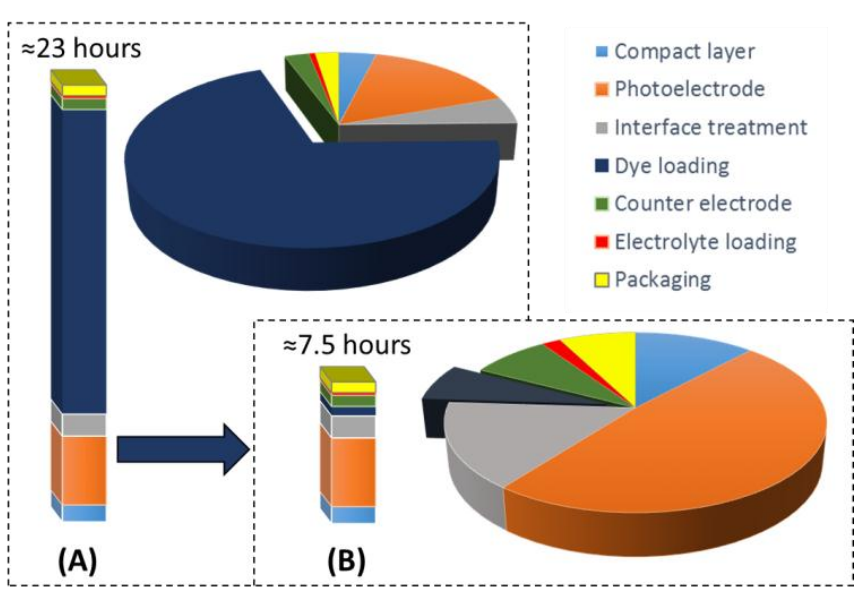

i

Fig. 6. Contribution of each major process to the average duration of DSC fabrication using (A) dip-coating ${ }^{28-35}$ and (B) FCD for dye sensitization. Overall, the DSC fabrication time is greatly reduced by using $F C D$, and dye loading is no longer the limiting factor.

\section{Supporting Information}

Materials and Methods: Synthetic procedure and characterization; Thermal gravimetric analysis; Fabrication of DSCs; Functionalized Carboxylate Deposition; Solar cell characterization; Kelvin Probe Force Microscopy; FTIR characterization. Supplemental Results and Discussion: Detailed Performance of FCS processed DSCs; Detailed Characterization of Surface Bonding and Film Growth.

\section{Acknowledgments}

This work was made possible by the National Science Foundation through joint funding by the Energy, Power, and Adaptive Systems (EPAS) Program in the Division of Electrical, Communications and Cyber Systems (ECCS) and the Electronic and Photonic Materials (EPM) Program in the Division of Materials Research (DMR), grant \#1102356. Additional funding was provided by the National Science Foundation/EPSCoR Grants No. 0554609 and 0903804 and the State of South Dakota. We thank the National Science Foundation Major Research Instrumentation Program (Grant Number CHE-0922816) for funding the AB SCIEX QTRAP 5500 LC-MS-MS housed in the South Dakota State University Campus Mass Spectrometry Facility which was supported by the National Science Foundation/EPSCoR Grant No. 0091948 and the State of South Dakota.

\section{References}

1. Grätzel, M., Dye-Sensitized Solar Cells. J. Photochem. Photobiol., C 2003, 4 (2), 145 153.

2. Hagfeldt, A.; Boschloo, G.; Sun, L.; Kloo, L.; Pettersson, H., Dye-Sensitized Solar Cells. Chem. Rev. 2010, 110 (11), 6595-6663.

3. Hardin, B. E.; Snaith, H. J.; McGehee, M. D., The Renaissance of Dye-Sensitized Solar Cells. Nat. Photonics 2012, 6 (3), 162-169.

4. Chung, I.; Lee, B.; He, J.; Chang, R. P.; Kanatzidis, M. G., All-Solid-State DyeSensitized Solar Cells with High Efficiency. Nature 2012, 485 (7399), 486-489.

5. Mathew, S.; Yella, A.; Gao, P.; HumphryBaker, R.; Curchod, B. F.; Ashari-Astani, N.; Tavernelli, I.; Rothlisberger, U.; Nazeeruddin, M. K.; Grätzel, M., Dye-Sensitized Solar Cells with 13\% Efficiency Achieved through the Molecular Engineering of Porphyrin Sensitizers. Nat. Chem. 2014, 6 (3), 242-247.

6. O'Regan, B.; Grätzel, M., Low Cost and Highly Efficient Solar Cells Based on the Sensitization of Colloidal Titanium Dioxide. Nature 1991, 335, 7377. 
7. Nazeeruddin, M. K.; Kay, A.; Rodicio, I.; Humphry-Baker, R.; Müller, E.; Liska, P.; Vlachopoulos, N.; Grätzel, M., Conversion of Light to Electricity by Cis-X2bis (2, 2'-Bipyridyl4, 4'-Dicarboxylate) Ruthenium (Ii) ChargeTransfer Sensitizers $\left(\mathrm{X}=\mathrm{Cl}^{-}, \mathrm{Br}^{-}, \mathrm{I}^{-}, \mathrm{Cn}^{-}\right.$, and $\mathrm{Scn}^{-}$ ) on Nanocrystalline Titanium Dioxide Electrodes. J. Am. Chem. Soc. 1993, 115 (14), 6382-6390.

8. Nazeeruddin, M. K.; Zakeeruddin, S.; Humphry-Baker, R.; Jirousek, M.; Liska, P.; Vlachopoulos, N.; Shklover, V.; Fischer, C.-H.; Grätzel, M., Acid-Base Equilibria of (2, 2'Bipyridyl-4, 4'-Dicarboxylic Acid) Ruthenium (Ii) Complexes and the Effect of Protonation on Charge-Transfer Sensitization of Nanocrystalline Titania. Inorg. Chem. 1999, 38 (26), 6298-6305.

9. Yella, A.; Lee, H.-W.; Tsao, H. N.; Yi, C.; Chandiran, A. K.; Nazeeruddin, M. K.; Diau, E. W.-G.; Yeh, C.-Y.; Zakeeruddin, S. M.; Grätzel, M., Porphyrin-Sensitized Solar Cells with Cobalt (Ii/Iii)-Based Redox Electrolyte Exceed 12 Percent Efficiency. Science 2011, 334 (6056), 629-634.

10. Hamann, T. W.; Jensen, R. A.; Martinson, A. B.; Van Ryswyk, H.; Hupp, J. T., Advancing Beyond Current Generation Dye-Sensitized Solar Cells. Energy Environ. Sci. 2008, 1 (1), 66-78.

11. Pagliaro, M.; Palmisano, G.; Ciriminna, R.; Loddo, V., Nanochemistry Aspects of Titania in Dye-Sensitized Solar Cells. Energy Environ. Sci. 2009, 2 (8), 838-844.

12. Jose, R.; Thavasi, V.; Ramakrishna, S., Metal Oxides for Dye- Sensitized Solar Cells. J. Am. Ceram. Soc. 2009, 92 (2), 289-301.

13. Zhang, Q.; Dandeneau, C. S.; Zhou, X.; Cao, G., Zno Nanostructures for Dye- Sensitized Solar Cells. Adv. Mater. 2009, 21 (41), $4087-$ 4108.

14. Mor, G. K.; Shankar, K.; Paulose, M.; Varghese, O. K.; Grimes, C. A., Use of HighlyOrdered Tio2 Nanotube Arrays in Dye-Sensitized Solar Cells. Nano lett. 2006, 6 (2), 215-218.

15. Hara, K.; Nishikawa, T.; Kurashige, M.; Kawauchi, H.; Kashima, T.; Sayama, K.; Aika, K.; Arakawa, H., Influence of Electrolyte on the Photovoltaic Performance of a Dye-Sensitized Tio $<$ Sub $>2</$ Sub $>$ Solar Cell Based on a Ru (Ii) Terpyridyl Complex Photosensitizer. Sol. Energy Mater. Sol. Cells 2005, 85 (1), 21-30.
16. Wu, J.; Hao, S.; Lan, Z.; Lin, J.; Huang, M.; Huang, Y.; Li, P.; Yin, S.; Sato, T., An AllSolid-State Dye-Sensitized Solar Cell-Based Poly (N-Alkyl-4-Vinyl-Pyridine Iodide) Electrolyte with Efficiency of 5.64\%. J. Am. Chem. Soc. 2008, 130 (35), 11568-11569.

17. Wang, P.; Dai, Q.; Zakeeruddin, S. M.; Forsyth, M.; MacFarlane, D. R.; Graetzel, M., Ambient Temperature Plastic Crystal Electrolyte for Efficient, All-Solid-State Dye-Sensitized Solar Cell. J. Am. Chem. Soc. 2004, 126 (42), 13590-13591.

18. Bai, Y.; Cao, Y.; Zhang, J.; Wang, M.; Li, R.; Wang, P.; Zakeeruddin, S. M.; Grätzel, M., High-Performance Dye-Sensitized Solar Cells Based on Solvent-Free Electrolytes Produced from Eutectic Melts. Nat. Mater. 2008, 7 (8), 626-630.

19. Nusbaumer, H.; Moser, J.-E.; Zakeeruddin, S. M.; Nazeeruddin, M. K.; Grätzel, M., Coii (Dbbip) 22+ Complex Rivals Tri-Iodide/Iodide Redox Mediator in DyeSensitized Photovoltaic Cells. J. Phys. Chem. B 2001, 105 (43), 10461-10464.

20. Snaith, H. J.; Moule, A. J.; Klein, C.; Meerholz, K.; Friend, R. H.; Grätzel, M., Efficiency Enhancements in Solid-State Hybrid Solar Cells Via Reduced Charge Recombination and Increased Light Capture. Nano Lett. 2007, 7 (11), 3372-3376.

21. Meng, Q.-B.; Takahashi, K.; Zhang, X.T.; Sutanto, I.; Rao, T.; Sato, O.; Fujishima, A.; Watanabe, H.; Nakamori, T.; Uragami, M., Fabrication of an Efficient Solid-State DyeSensitized Solar Cell. Langmuir 2003, 19 (9), 3572-3574.

22. Bach, U.; Lupo, D.; Comte, P.; Moser, J.; Weissörtel, F.; Salbeck, J.; Spreitzer, H.; Grätzel, M., Solid-State Dye-Sensitized Mesoporous Tio2 Solar Cells with High Photon-to-Electron Conversion Efficiencies. Nature 1998, 395 (6702), 583-585.

23. Kovash Jr, C. S.; Hoefelmeyer, J. D.; Logue, B. A., Tioz Compact Layers Prepared by Low Temperature Colloidal Synthesis and Deposition for High Performance Dye-Sensitized Solar Cells. Electrochim. Acta 2012, 67, 18-23.

24. Ito, S.; Murakami, T. N.; Comte, P.; Liska, P.; Grätzel, C.; Nazeeruddin, M. K.; Grätzel, M., Fabrication of Thin Film Dye Sensitized Solar Cells with Solar to Electric 
Power Conversion Efficiency over 10\%. Thin Solid Films 2008, 516 (14), 4613-4619.

25. Law, M.; Greene, L. E.; Johnson, J. C.; Saykally, R.; Yang, P., Nanowire Dye-Sensitized Solar Cells. Nat. Mater. 2005, 4 (6), 455-459.

26. Zhu, K.; Neale, N. R.; Miedaner, A.; Frank, A. J., Enhanced Charge-Collection Efficiencies and Light Scattering in DyeSensitized Solar Cells Using Oriented Tio2 Nanotubes Arrays. Nano Lett. 2007, 7 (1), 69-74.

27. Kim, J. Y.; Noh, J. H.; Zhu, K.; Halverson, A. F.; Neale, N. R.; Park, S.; Hong, K. S.; Frank, A. J., General Strategy for Fabricating Transparent Tioz Nanotube Arrays for Dye-Sensitized Photoelectrodes: Illumination Geometry and Transport Properties. ACS nano 2011, 5 (4), 2647-2656.

28. Shrestha, M.; Si, L.; Chang, C.-W.; He, H.; Sykes, A.; Lin, C.-Y.; Diau, E. W.-G., Dual Functionality of Bodipy Chromophore in Porphyrin-Sensitized Nanocrystalline Solar Cells. J. Phys. Chem. C 2012, 116 (19), 10451-10460.

29. Hara, K.; Wang, Z.-S.; Sato, T.; Furube, A.; Katoh, R.; Sugihara, H.; Dan-oh, Y.; Kasada, C.; Shinpo, A.; Suga, S., OligothiopheneContaining Coumarin Dyes for Efficient DyeSensitized Solar Cells. J. Phys. Chem. B 2005, 109 (32), 15476-15482.

30. Ito, S.; Zakeeruddin, S. M.; HumphryBaker, R.; Liska, P.; Charvet, R.; Comte, P.; Nazeeruddin, M. K.; Péchy, P.; Takata, M.; Miura, H., High- Efficiency Organic- DyeSensitized Solar Cells Controlled by Nanocrystalline- Tioz Electrode Thickness. $A d v$. Mater. 2006, 18 (9), 1202-1205.

31. Bessho, T.; Zakeeruddin, S. M.; Yeh, C. Y.; Diau, E. W. G.; Grätzel, M., Highly Efficient Mesoscopic Dye- Sensitized Solar Cells Based on Donor-Acceptor- Substituted Porphyrins. Angew. Chem. Int. Ed. 2010, 49 (37), 6646-6649. 32. Hsieh, C.-P.; Lu, H.-P.; Chiu, C.-L.; Lee, C.-W.; Chuang, S.-H.; Mai, C.-L.; Yen, W.-N.; Hsu, S.-J.; Diau, E. W.-G.; Yeh, C.-Y., Synthesis and Characterization of Porphyrin Sensitizers with Various Electron-Donating Substituents for Highly Efficient Dye-Sensitized Solar Cells. J. of Mater. Chem. 2010, 20 (6), 1127-1134.

33. Zhu, W.; Wu, Y.; Wang, S.; Li, W.; Li, X.; Chen, J.; Wang, Z. s.; Tian, H., Organic Da- П- a Solar Cell Sensitizers with Improved
Stability and Spectral Response. Adv. Funct. Mater. 2011, 21 (4), 756-763.

34. Ko, S.; Choi, H.; Kang, M.-S.; Hwang, H.; Ji, H.; Kim, J.; Ko, J.; Kang, Y., SiloleSpaced Triarylamine Derivatives as Highly Efficient Organic Sensitizers in Dye-Sensitized Solar Cells (Dsscs). J. Mater. Chem. 2010, 20 (12), 2391-2399.

35. Choi, H.; Baik, C.; Kang, S. O.; Ko, J.; Kang, M. S.; Nazeeruddin, M. K.; Grätzel, M., Highly Efficient and Thermally Stable Organic Sensitizers for Solvent- Free Dye- Sensitized Solar Cells. Angew. Chem. 2008, 120 (2), 333336.

36. Li, F.; Jennings, J. R.; Wang, Q.; Chua, J.; Mathews, N.; Mhaisalkar, S. G.; Moon, S.-j.; Zakeeruddin, S. M.; Grätzel, M., Determining the Conductivities of the Two Charge Transport Phases in Solid-State Dye-Sensitized Solar Cells by Impedance Spectroscopy. J. Phys. Chem. C 2013.

37. Chandiran, A. K.; Yella, A.; Stefik, M.; Heiniger, L.-P.; Comte, P.; Nazeeruddin, M. K.; Grätzel, M., Low-Temperature Crystalline Titanium Dioxide by Atomic Layer Deposition for Dye-Sensitized Solar Cells. ACS Appl. Mater. Interfaces 2013, 5 (8), 3487-3493.

38. Kitamura, T.; Ikeda, M.; Shigaki, K.; Inoue, T.; Anderson, N. A.; Ai, X.; Lian, T.; Yanagida, S., Phenyl-Conjugated Oligoene Sensitizers for Tion Solar Cells. Chem. Mater. 2004, 16 (9), 1806-1812.

39. Marinado, T.; Nonomura, K.; Nissfolk, J.; Karlsson, M. K.; Hagberg, D. P.; Sun, L.; Mori, S.; Hagfeldt, A., How the Nature of Triphenylamine-Polyene Dyes in Dye-Sensitized Solar Cells Affects the Open-Circuit Voltage and Electron Lifetimes. Langmuir 2009, 26 (4), 25922598.

40. $\mathrm{Xu}, \mathrm{W} . ;$ Cai, F., New Triphenylamine-Based Dyes for Dye-Sensitized Solar Cells. J. Phys. Chem. C 2008, 112 (3), 874-880.

41. Teng, C.; Yang, X.; Yang, C.; Tian, H.; Li, S.; Wang, X.; Hagfeldt, A.; Sun, L., Influence of Triple Bonds as П-Spacer Units in Metal-Free Organic Dyes for Dye-Sensitized Solar Cells. J. Phys. Chem. C 2010, 114 (25), 11305-11313.

42. Hara, K.; Sato, T.; Katoh, R.; Furube, A.; Yoshihara, T.; Murai, M.; Kurashige, M.; Ito, S.; Shinpo, A.; Suga, S., Novel Conjugated Organic 
Dyes for Efficient Dye- Sensitized Solar Cells. Adv. Funct. Mater. 2005, 15 (2), 246-252.

43. Sommeling, P.; O'regan, B.; Haswell, R.; Smit, H.; Bakker, N.; Smits, J.; Kroon, J.; Van Roosmalen, J., Influence of a Ticl4 PostTreatment on Nanocrystalline Tio2 Films in DyeSensitized Solar Cells. J. Phys. Chem. B 2006, 110 (39), 19191-19197.

44. Thavasi, V.; Renugopalakrishnan, V.; Jose, R.; Ramakrishna, S., Controlled Electron Injection and Transport at Materials Interfaces in Dye Sensitized Solar Cells. Matr. Sci. Eng. $R$ 2009, 63 (3), 81-99.

45. Horiuchi, T.; Miura, H.; Sumioka, K.; Uchida, S., High Efficiency of Dye-Sensitized Solar Cells Based on Metal-Free Indoline Dyes. J. Am. Chem. Soc. 2004, 126 (39), 12218-12219. 46. Liu, W.-H.; Wu, I.-C.; Lai, C.-H.; Lai, C.H.; Chou, P.-T.; Li, Y.-T.; Chen, C.-L.; Hsu, Y.Y.; Chi, Y., Simple Organic Molecules Bearing a 3, 4-Ethylenedioxythiophene Linker for Efficient Dye-Sensitized Solar Cells. Chem. Commun. 2008, (41), 5152-5154.

47. Horiuchi, T.; Miura, H.; Uchida, S., Highly-Efficient Metal-Free Organic Dyes for Dye-Sensitized Solar Cells. Chem. Commun. 2003, (24), 3036-3037.

48. Campbell, W. M.; Burrell, A. K.; Officer, D. L.; Jolley, K. W., Porphyrins as Light Harvesters in the Dye-Sensitised Tioz Solar Cell. Coord. Chem. Rev. 2004, 248 (13), 1363-1379.

49. Nonnenmacher, M.; o'Boyle, M.; Wickramasinghe, H., Kelvin Probe Force Microscopy. Appl. Phys. Lett. 1991, 58, 2921.

50. Deacon, G.; Phillips, R., Relationships between the Carbon-Oxygen Stretching Frequencies of Carboxylato Complexes and the Type of Carboxylate Coordination. Coord. Chem. Rev 1980, 33 (3), 227-250. 